\title{
Correction to: Improvement in systematic error in background-oriented schlieren results by using dynamic backgrounds
}

\author{
Frieder Reichenzer ${ }^{1,2} \cdot$ Mike Schneider $^{1} \cdot$ Alois Herkommer $^{1,2}$
}

Published online: 10 October 2021

๑) Springer-Verlag GmbH Germany, part of Springer Nature 2021

\section{Correction to: Experiments in Fluids (2021) 62:196 \\ https://doi.org/10.1007/s00348-021-03285-6}

After publication in Vol 62 Issue 9, the corresponding author Frieder Reichenzer decided to add his second affiliation as Institute of Applied Optics (ITO), University of Stuttgart, Pfafenwaldring 9, 70569 Stuttgart, Germany.

Publisher's Note Springer Nature remains neutral with regard to jurisdictional claims in published maps and institutional affiliations.

The original article can be found online at https://doi.org/10.1007/ s00348-021-03285-6.

Frieder Reichenzer

f.reichenzer@live.com

1 TRUMPF Laser- Und Systemtechnik GmbH, Johann-Maus-Str. 2, 71254 Ditzingen, Germany

2 Institute of Applied Optics (ITO), University of Stuttgart, Pfafenwaldring 9, 70569 Stuttgart, Germany 